\title{
In this issue
}

\section{Bolwijn and Kumpe's "Human Resource Management"}

Bolwijn and Kumpe from The Netherlands have prepared a much needed discussion of the facts and fiction in Human Resource Management (HRM). This confused and prematurely emerged area has recognized the role of employees and human capital, but failed to recognize the declining role of labor, the increasing role of knowledge and the demise of the division of labor and vertical hierarchy and its replacement by autonomous teams in horizontal organizations, carrying out highly integrated tasks and work assignments.

The authors are among only a few HRM researchers who recognize these weaknesses and are aware of the need to reorient HRM quite decisively.

The authors have recognized that the evolution of customer demand is shifting rapidly towards uniqueness, innovation and speed - what is called mass customization. They are also quite modern in recognizing that these new dimensions (efficiency, quality, flexibility and innovation) have to be met simultaneously and are not subject to 'making right tradeoffs'. Such insights are quite rare among HRM followers and so increase the quality and attractiveness of this paper for Human Systems Management (HSM).

There is a big difference between HSM and HRM: these two areas intersect only where HRM takes the actual management system into account. Some general, non-systemic HRM that are capable of talking about the human factor without for example recognizing the problems of embedding HRM in either vertical or horizontal organization, are of no interest to HSM.

The onset of flexible, tradeoffs-free firms based on the global management paradigm (GMP) cannot be missed by HRM. During this phase HRM frequently misses the boat in achieving true decentralization of authority and a more coaching and supporting style of management. HRM has hardly been instrumental in strengthening autonomous teamwork, boosting decision-making independence, promoting reintegration of task, labor and knowledge, and fighting for employees' share in capital ownership. Questions of participation and democratization, so crucial for con- tinuous and autonomous innovation and prerequisites of the innovative firm, have been rarely addressed.

The problem is that if HRM cannot become helpful in all these transformations, firms will have to do it anyway, without HRM. Some other function will emerge, like Knowledge Management, and take over the challenges where others failed.

\section{Nodoushani and Nodoushani's "Management education"}

Business schools are about to start rethinking and reengineering the purpose of their mission and business. Professors Nodoushani believe that the future of management education depends upon rethinking of the theory of knowledge that guides the growing interest in managerial learning and training.

The reason is simple. Knowledge has become the primary form of capital, replacing labor, technology and money. Knowledge is becoming scarce and companies and countries which produce knowledge well, produce all other things even better. Societies which have recently neglected knowledge production, like Russia and Central Europe, are going to slide even lower in their lukewarm effort to catch up with developed countries. There is no substitute for knowledge.

The Nodoushanis trace the evolution of business education from the School of Commerce, School of Business and School of Business Administration to School of Management and, possibly, to the School of Managerial Knowledge. They call for professionalization of management, conforming to recognized standards of learning and training.

The purpose of professional education is not to teach a narrowly defined set of skills as measured by formal examinations, but to define a set of general principles that recruits the apprentice into the profession. The apprentice learns a profession through action and experimentation and becomes a professional through knowledge, behavior and acceptance of the code and principles of the profession.

Professional management has not been born yet: simply being paid exorbitant sums does not identify a professional. In fact, some professionals in some countries are at the bottom of the income ladder (med- 
ical doctors in Central Europe, lawyers in Asia, etc.). The only capital of a professional is his mind, sense of ethics and public service, knowledge and group identification.

Entrepreneurs, managers, singers and soccer players can be paid for their services but their professionality rarely compares to that of traditional professions in medicine, sciences and social services.

The Nodoushanis are not the first ones calling for the professionalization of management and certainly not the last ones. Yet, management keeps resisting, even though from a steadily weakening position. Within a decade or so, after the horizontal organization has established itself more firmly, the professionalization of management will become more visible and even more necessary.

\section{Kline et al.'s "Team effectiveness"}

Kline, MacLeod and McGrath of Calgary have conducted a study of team effectiveness with special emphasis on contributing and hindering factors, both internal and external to teams, as viewed by the team members and participants themselves.

The results confirmed conventional wisdom that the factors that most hinder a team's performance are external to the team and those that most contribute to its effectiveness are internal to the team. In other words, management and organizational milieu can harm teams quite effectively, but it cannot help them too effectively either: the teams have to do it themselves, be autonomous and self-managing.

This is why teamwork in a hierarchical organization is really an oxymoron. There is no effective teamwork in systems of command. Teamwork is natural and effective in horizontal organizations.

Support of teams via organizational context and conditions is a necessary but not sufficient condition to promote team effectiveness. However, the factors that put teams into the 'effective' category are those variables that are specific to the team members themselves.

Relative strength of the external and internal factors is difficult to assess. Most likely, even a good team can be ruined by an unhealthy or unsupportive milieu, but even the best of conditions and circumstances cannot save an incoherent, unmotivated and non-interacting team.

As the authors conclude, both internal and external factors could be equally important and in terms of per- formance inseparable. Attempting to establish priorities between these two groups of factors may turn out to be futile unpredictive. There seems to be a number of external and internal (but far more external) factors that must be in place before team effectiveness can occur. Only then can a host of internal factors really 'kick in' and contribute to team effectiveness.

Examples of contributing externals are climate, management support, clear goal setting and decisionmaking autonomy. Among the contributing internals would be cooperation, trust and respect, shared values, commitment, communication and leadership.

Examples of hindering externals would be lack of decision-making autonomy, lack of goals, too much bureaucracy, non-adaptability to change, and so on. Among the hindering internals would be lack of communication, lack of social cohesion, lack of employee commitment and team conflict.

Team effectiveness is of great importance and these kinds of studies are more than welcome.

\section{Midttun et al.'s "Market outcomes under different behaviors"}

Midttun, Bakken and Wenst $\varnothing p$ from the Norwegian School of Management have explored the implications of different behavioral assumptions for market outcomes, especially in terms of price formation and market stability.

Three ideal behavioral archetypes have been assumed: the Rational man, the Normfollowing man, and the Emotional man. What are the effects of rational calculation, crowd and norm following and emotional and spontaneous decision making on a free market outcome?

A simulation model of the Norwegian electricity market is a free trade model with more than $130 \mathrm{ac}-$ tors. The simulation has found that given a market with exogenously generated shifts in supply, the existence of some actors with emotional and normativelyoriented behavior will significantly affect price fluctuations when compared with a similar market with only rational actors.

A shift from rational to emotional actors creates dramatic changes in price development with dramatic peaks and volatility. An increase in emotional behavior not only amplifies oscillations in market prices, but also affects the periodization of the cycles.

Part of the volatility of stock markets can be attributed to emotional and normfollowing behavior, 
which are the norm in such markets, and contrast with the stability of industrial and even agricultural products where much more rational and insightful decision making prevails. Certain markets are not dominated by rational agents but also do not allow rational agents to operate properly due to speed, lack of insight and role of uncertainty. Such markets are bound to be volatile and also attract volatility-inducing behavior.

The Norwegian simulation models have suggested that actor-orientation may have an important if not decisive impact on price development. Neglecting this could lead to a fatal flaw in understanding the markets.
The experiments also suggest that price developments and equilibrium formation can be better and more comprehensively understood through simulations rather than through traditional mathematical analysis. The latter is quite inadequate for describing complexity and complex behavior. Where mathematical economics failed to unveil a so-called 'invisible hand', simulation modeling still provides an alternative and a chance of finally lifting the medieval overskirts of economics and make the invisible visible at last. 